\title{
Experimental investigation of propagation mechanisms and fracture morphology for coalbed methane reservoirs
}

\author{
Chi $\mathrm{Ai}^{1} \cdot$ Xiao-Xuan $\mathrm{Li}^{1} \cdot$ Jun Zhang ${ }^{1} \cdot$ Dan Jia ${ }^{1} \cdot$ Wen-Jing $\operatorname{Tan}^{2}$
}

Received: 18 February 2018 / Published online: 26 July 2018

(C) The Author(s) 2018

\begin{abstract}
Fracture propagation mechanisms in coalbed methane (CBM) reservoirs are very complex due to the development of the internal cleat system. In this paper, the characteristics of initiation and propagation of hydraulic fractures in coal specimens at different angles between the face cleat and the maximum horizontal principal stress were investigated with hydraulic fracturing tests. The results indicate that the interactions between the hydraulic fractures and the cleat system have a major effect on fracture networks. "Step-like" fractures were formed in most experiments due to the existence of discontinuous butt cleats. The hydraulic fractures were more likely to divert or propagate along the butt cleat with an increase in the angles and a decrease in the horizontal principal stress difference. An increase in the injection rate and a decrease in the fracturing fluid viscosity were more conducive to fracture networks. In addition, the influence on fracture propagation of the residual coal fines in the wellbore was also studied. The existence of coal fines was an obstacle in fracturing, and no effective connection can be formed between fractures. The experimental investigation revealed the fracture propagation mechanisms and can provide guidance for hydraulic fracturing design of CBM reservoirs.
\end{abstract}

Keywords Coalbed methane reservoir · Butt cleat · Propagation mechanisms · Fracture morphology $\cdot$ Step-like fractures

\section{Introduction}

Hydraulic fracturing (Ma et al. 2014, 2017a; Taleghani et al. 2016; Wang et al. 2018; Zhang 2014), is a very important technology and has been successfully applied to the industrialized development of coalbed methane (CBM) to improve low coalbed permeability (Alexis et al. 2015; Qin et al. 2018; Wu et al. 2018). Different from singlejointed rock, such as shale, the cleat system developed in coal can generate complex and diverse fractures. There is a lack of an effective method for visualization of fractures in underground coal seams, and numerical simulation of coal

Edited by Yan-Hua Sun

Jun Zhang

zhangjun410410@163.com

Chi Ai

aichi2017@163.com

1 College of Petroleum Engineering, Northeast Petroleum University, Daqing 163318, Heilongjiang, China

2 College of Geoscience and Technology, China University of Petroleum (East China), Qingdao 266580, Shandong, China seam fracturing based on ideal hypotheses can hardly reflect the true regime of fracture propagation. However, fracturing experiments in laboratory can simulate the initiation and propagation process in CBM reservoirs under real stress conditions, which can reveal complex fracture propagation mechanisms for CBM reservoirs.

The mechanisms of fracture extension and the description of fracture morphology in CBM reservoirs have always been topical but difficult areas of research (Porcu et al. 2013; Wang et al. 2017; Wright et al. 1995; Zhang et al. 2016; Zhao et al. 2016; Zou et al. 2017). The uniquely developed internal cleat system (Abass et al. 1990) makes a great difference in hydraulic fracture propagation mechanisms between CBM reservoirs and other conventional oil and gas reservoirs. Hydraulic fractures may propagate along weak structural planes (bedding planes, cleats or secondary joints, etc.), making the extension extremely complex and even forming complex fracture extension areas or complex fracturing zones. Hou et al. (2013) carried out a series of hydraulic fracturing experiments into mechanical parameters and established hydraulic fracture initiation criteria for a horizontal well in a coal seam. Deng et al. (2016) investigated the effects of notch angle, notch 
length and injection rate on directional hydraulic fracturing initiation and propagation. Ma et al. (2017b) revealed the mechanism of hydraulic fracture growth in a conglomerate reservoir based on a series of laboratory tests. Lin et al. (2017) demonstrated the effect of anisotropy of shale on hydraulic fracture propagation and found that the bedding plane angle has a significant influence on fracturing results. Huang et al. (2017) observed the initiation of natural fractures and propagation direction in coal seams under different in situ stresses.

In order to accurately monitor fracture initiation location and actual propagation path, acoustic emission has also been applied to hydraulic fracturing experiments. Chitrala et al. (2013) studied the acoustic emission monitoring results of Lyons sandstone samples under different applied stress conditions. Lu et al. (2016) established a three-dimensional model to assess initiation location in coal. The initiation was monitored by an acoustic emission system, and the results were consistent with the model calculation. Liang et al. (2017) divided the whole hydraulic fracturing process of coal into four stages: microcrack formation, fracture initiation, unstable crack propagation and fracture closure, and monitored the orientation of fractures by acoustic emission.

Many scholars have also carried out laboratory experiments to investigate the effect of natural fractures on hydraulic fracture propagation. Liang et al. (2016) investigated the influence of in situ stress, tensile strength and natural macro-cracks on crack formation and propagation. Fu et al. (2016) studied the influence of partially and strongly cemented natural fractures on hydraulic fracture propagation. Dehghan et al. (2015a, b) investigated the influence of pre-existing fracture dip and strike on fracture propagation based on research of predecessors (Blanton 1986; Warpinski and Teufel 1987). Additionally, the influence of injection rate and viscosity of fracturing fluid, elastic modulus and other factors have also been widely investigated (Guo et al. 2014; Jiang et al. 2016; Wang et al. 2016b; Westwood et al. 2017; Zou et al. 2016). Scholars (Liu et al. 2014; Tan et al. 2017b) have also found that the propagation path of fractures followed certain principles, namely the least resistance and the most preferred propagation path. In addition, some researchers (Ding et al. 2018; Huang et al. 2017; Song et al. 2014; Wang et al. 2016a, 2017; Yao et al. 2018; Zhou et al. 2016; Zou et al. 2017) also analyzed the effects of the above factors by numerical simulation. The simulation results also proved that approach angle, horizontal principal stress difference and development of natural fractures are the main factors affecting the propagation orientation. However, the numerical simulation method cannot truly simulate the cohesion between natural fractures, leading to a discrepancy between simulation results and the actual propagation.
Although theoretical and experimental studies of hydraulic fracturing of unconventional reservoirs have been carried out, the propagation mechanisms of hydraulic fractures in coal are very complex due to the existence of face and butt cleats and scholars have not reached a unified understanding of its propagation mechanisms, so hydraulic fracture propagation morphology in coal is still not able to be described accurately. In this paper, experiments for cubic raw coal specimens at different angles between the face cleat and the maximum horizontal principal stress were carried out to analyze fracture propagation characteristics. The effects of horizontal principle stress difference, horizontal principle stress difference coefficient and fluid viscosity on fracture propagation were also analyzed qualitatively and quantitatively. Furthermore, experiments of different injection rates at $90^{\circ}$ and $0^{\circ}$ were investigated to study the effect of butt cleats on fracture complexity. In addition, since a large amount of coal fines was generated during drilling and was difficult to clean up, the effect of coal fines on fracturing was innovatively considered. The results can reveal the mechanisms of fracture propagation and provide a theoretical basis for fracturing development design of CBM reservoirs.

\section{Experimental method}

\subsection{Material characteristics and specimen preparation}

The coal used in this study was from the Zhangchen Mine, Jixi Colliery, Heilongjiang Province, northeast China. The depth of coal seams is $300-450 \mathrm{~m}$, and the average thickness is about $1.8 \mathrm{~m}$. The coal is anthracite, with calcite, kaolinite and quartz. There is a higher content of vitrinite than exinite and inertinite. The cleats and bedding planes are extremely developed in coal (Abass et al. 1991). In order to obtain reliable data on cleats and bedding plane intervals, the distances between bedding planes, face cleats and butt cleats were separately measured using macroscopic measurements and SEM images (Figs. 1, 2). The average length of the bedding plane is $186 \mathrm{~mm}$, while the interval is $35 \mathrm{~mm}$. As for face cleats, their average length is $173 \mathrm{~mm}, 160 \mathrm{~mm}$ longer than butt cleats. The interval is $13 \mathrm{~mm}$ for face cleats and $21 \mathrm{~mm}$ for butt cleats.

According to experimental requirements, the raw coal was cut into cubic specimens with dimensions of $300 \mathrm{~mm}$. However, due to the well-developed cleat system and low strength of coal, it is very difficult to ensure the required dimensions for field-sampling. Therefore, a standard specimen was prepared by wrapping it with a material similar to raw coal. Firstly, the raw coal was cut into coal blocks whose sizes are slightly smaller than the standard 


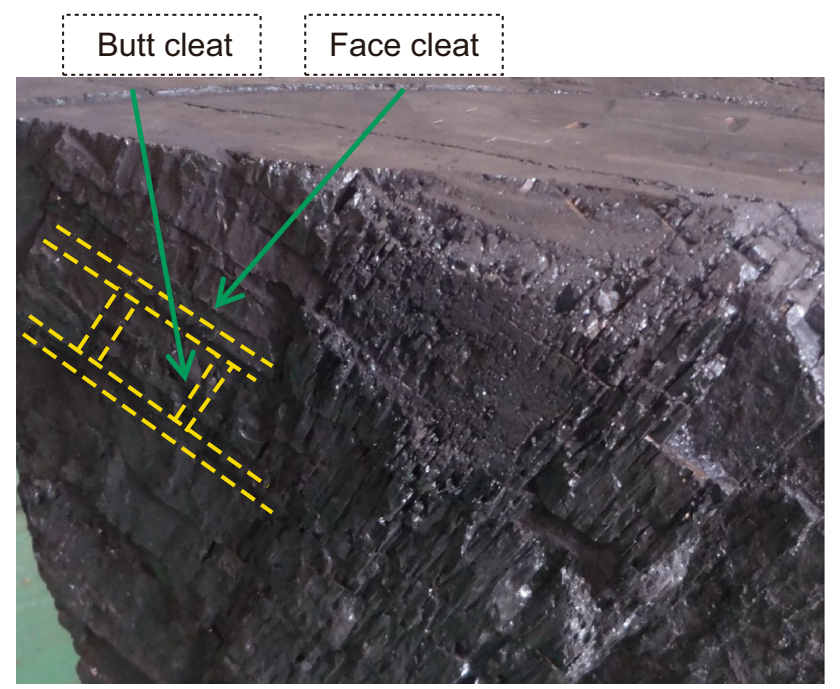

Fig. 1 Macroscopic measurements of cleats

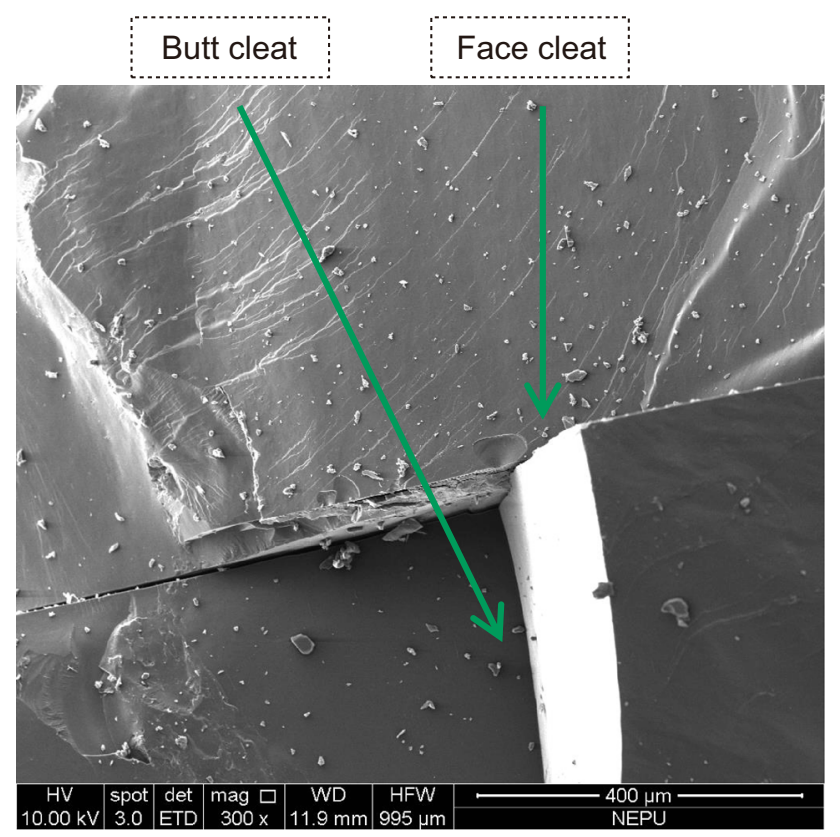

Fig. 2 SEM image of cleats

specimen size. Meantime, we ensured that the bedding plane is parallel to the horizontal plane and the raw coal was cut along different cleat orientations. In accordance with previous experimental experience and related principles, coal fines with particle size of 40-60 mesh, gypsum powder and Portland cement (No. 32.5) were mixed in the ratio of 1:1:3. The mechanical properties of similar materials were then tested, and the results indicated that the average compressive strength, tensile strength and elastic modulus were $12.2,0.63$, and $5431 \mathrm{MPa}$, which were extremely close to the specimen mechanical parameters in the tests. Secondly, the coal blocks were placed in the center of the mold and the evenly mixed similar materials were poured into the mold for casting. After pouring, a rubber hammer was used to beat the mold around to discharge excess air bubbles. Finally, the specimens were maintained for consolidation for more than 30 days.

The specimen was placed on a vertical drilling machine after maintenance, and a 150-mm-deep hole was drilled in the center by a carbide bit with an outer diameter of $11 \mathrm{~mm}$ to simulate an actual borehole. Some of the boreholes were thoroughly cleaned up and dried, while two remained unwashed. The length, outer and inner diameters of the simulated wellbore are 160,10 and $8 \mathrm{~mm}$, respectively (Fig. 3), and a sealing ring for fracturing was installed as shown in Fig. 4.

\subsection{Experimental apparatus}

Figure 5 presents a true tri-axial hydraulic fracturing test system, which consists of (I) a true tri-axial model block, (II) a hydraulic fracturing pump pressure servo control system and (III) a data collection system. Part I consists of a specimen placement chamber, a cubic block to pressurize the specimen, and a hydraulic pump to drive the block. The true tri-axial loading device can simulate the true in situ stress in three directions and provide a maximum confining pressure of $150 \mathrm{MPa}$ for rocks of $300 \mathrm{~mm} \times 300 \mathrm{~mm} \times$ $300 \mathrm{~mm}$. Part II includes a control box and a high-pressure injection pump. Two modes, constant injection pressure or constant injection rate, can be selected in the experiment, with a maximum pumping pressure of $40 \mathrm{MPa}$.

\subsection{Experimental methods and procedures}

The purpose of this experiment is to investigate fracture propagation mechanisms and to determine the effect of cleat system on fracture morphology for CBM reservoirs. To investigate the effects of different angles between the

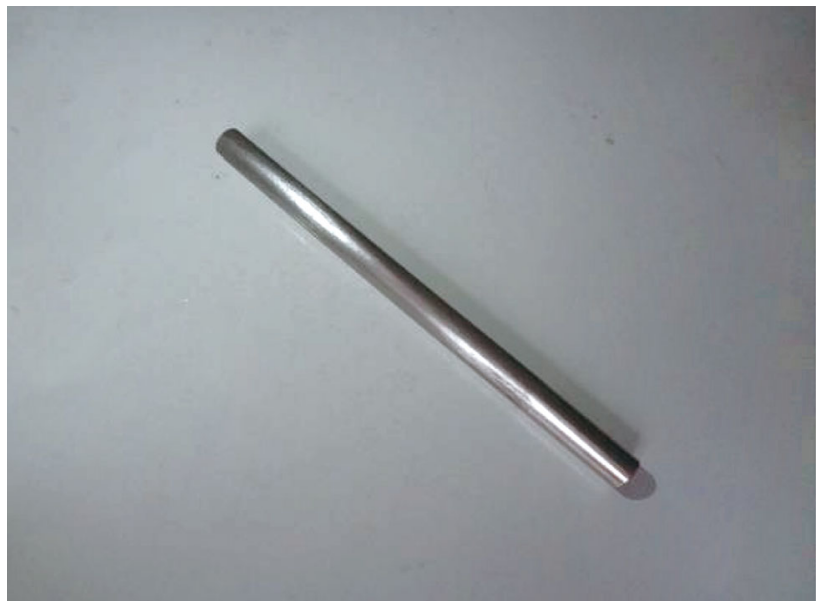

Fig. 3 Steel pipe 


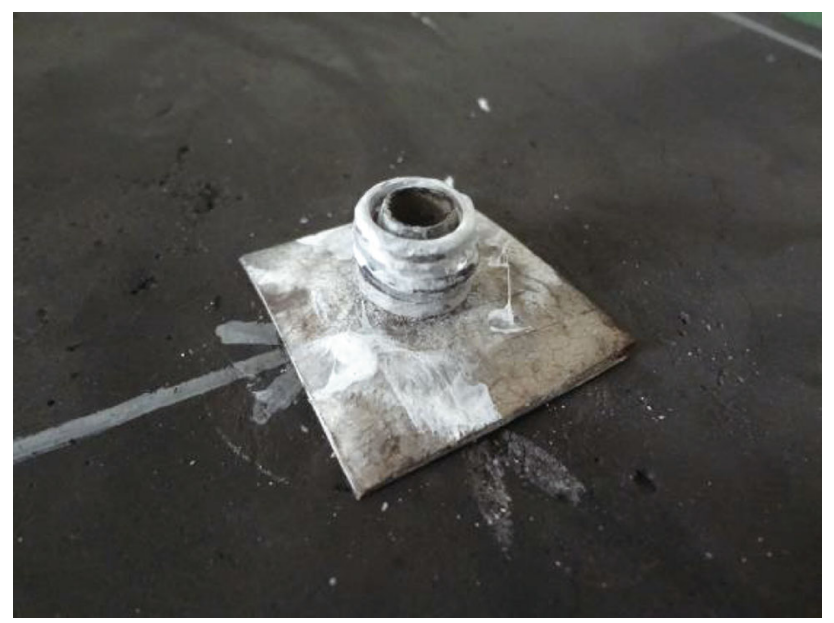

Fig. 4 Sealing ring

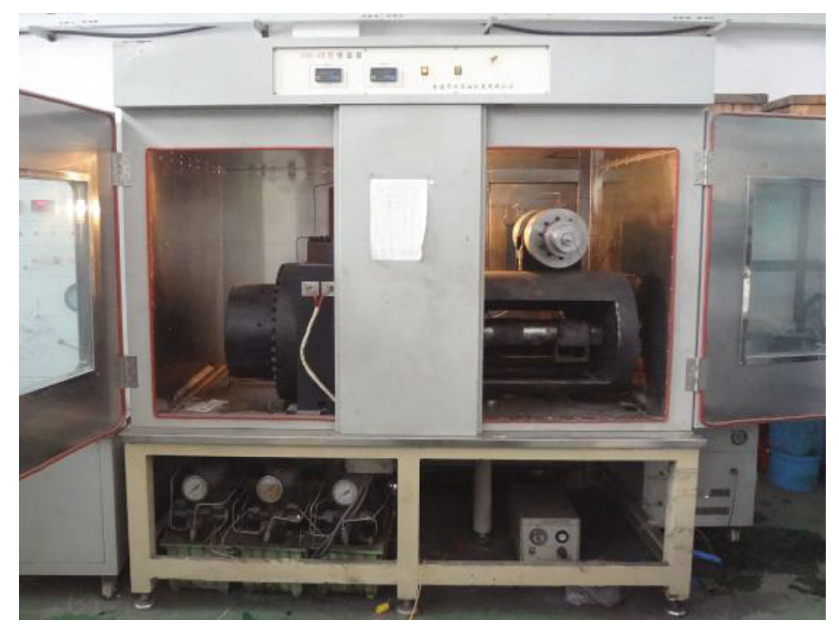

Fig. 5 True tri-axial hydraulic fracturing system

face cleat and the maximum horizontal principal stress, in situ stress, injection rate and fluid viscosity on fracture propagation, orthogonal experimentation was designed in this study. The specimens were prepared along different cleat orientations. The angles between the face cleat and the maximum horizontal principal stress are $0^{\circ}, 30^{\circ}, 60^{\circ}$ and $90^{\circ}$. For each experiment, fracturing fluid was injected with non-penetrating white dye additive to highlight the propagation path. The additive has no influence on rheological properties of the fracturing fluid. The cases are selected as shown in Table 1.

The specific process of the experiment was as follows:

(a) Place the prepared specimen in the chamber, and a thin Teflon sheet covered on both sides with Vaseline was inserted between the confining pressure loading platen and the specimen to prevent shear stress (de Pater and Beugelsdijk 2005). Start the confining pressure loading system to complete the three-dimensional stress loading.

(b) Start the hydraulic servo pump pressure system to inject the fracturing fluid into the simulated wellbore. The data were collected in real time with a computer.

(c) Once the injection pressure decreased gradually to a stable value and the fracturing fluid reached the boundary of the specimen, the fracturing pumping was stopped. The true tri-axial system was unloaded to zero smoothly, and the experiment was finished. The specimen was removed and split subsequently. The white dye clearly showed the actual propagation path of hydraulic fractures.

\section{Experimental results and discussion}

\subsection{Analysis of the pumping pressure curves}

Figure 6 presents pumping pressure curves under different cleat orientations. There was no obvious differentiation stage in the fracturing process of coal, which was different from that in shale (Tan et al. 2017c). The fluctuation process was relatively more obvious and intense in accordance with the developed cleat system. The existence of the butt cleat makes the coal generate a large number of hydraulic fractures connected with coal during fracturing, resulting in frequent opening and closing of cleats, which shows apparent fluctuation on the pumping pressure curves. Ma et al. (2017b) noted that the pumping pressure decreased sharply to a level less than the minimum horizontal principle stress after it reached the breakdown pressure in conglomerate specimens, indicating that the fluid flowed into the fracture and produced a certain resistance after the fracture opened. The pumping pressure did not reach the minimum horizontal principle stress in the entire fracturing process of coal, which may be related to its developed cleat system. Although a large amount of fluid was injected, it is difficult to build up a high pumping pressure. In addition, the pumping pressure in the process of propagation was always lower than the breakdown pressure, which indicated that the stress always concentrated near the wellbore or within a certain range.

When the face cleat was parallel to the maximum horizontal principle stress (Fig. 6a), a large amount of fracturing fluid was injected into the simulated wellbore. The pumping pressure increased gradually and dropped suddenly when the breakdown pressure was reached, that is, the peak of the pumping pressure curve. A strong energy release was generated at the moment of initiation and a main fracture was formed in the specimen. Subsequently, 
Table 1 Experimental scheme of the true tri-axial fracturing simulation

\begin{tabular}{|c|c|c|c|c|c|c|c|}
\hline \multirow[t]{2}{*}{ Specimen number } & \multirow[t]{2}{*}{$\alpha,{ }^{\circ}$} & \multicolumn{3}{|c|}{ In situ stress, $\mathrm{MPa}$} & \multirow[t]{2}{*}{$K_{\mathrm{h}}$} & \multirow[t]{2}{*}{ Injection rate, $\mathrm{mL} / \mathrm{min}$} & \multirow[t]{2}{*}{ Fracturing fluid viscosity, $\mathrm{mPa} s$} \\
\hline & & $\sigma_{\mathrm{v}}$ & $\sigma_{\mathrm{H}}$ & $\sigma_{\mathrm{h}}$ & & & \\
\hline \#1 & 0 & 12 & 8 & 4 & 1.00 & 1.5 & 25.4 \\
\hline$\# 2$ & 30 & 12 & 8 & 4 & 1.00 & 1.5 & 25.4 \\
\hline \#3 & 60 & 12 & 8 & 4 & 1.00 & 1.5 & 25.4 \\
\hline \#4 & 90 & 12 & 8 & 4 & 1.00 & 1.5 & 25.4 \\
\hline \#5 & 0 & 12 & 6 & 4 & 0.50 & 1.5 & 25.4 \\
\hline \#6 & 0 & 12 & 10 & 8 & 0.25 & 1.5 & 25.4 \\
\hline \#7 & 0 & 12 & 4 & 2 & 1.00 & 1.5 & 25.4 \\
\hline \#8 & 0 & 12 & 10 & 6 & 0.67 & 1.5 & 25.4 \\
\hline \#9 & 90 & 12 & 4 & 2 & 1.00 & 0.5 & 25.4 \\
\hline \#10 & 90 & 12 & 4 & 2 & 1.00 & 1.5 & 25.4 \\
\hline \#11 & 90 & 12 & 4 & 2 & 1.00 & 15 & 25.4 \\
\hline \#12 & 0 & 12 & 4 & 2 & 1.00 & 15 & 25.4 \\
\hline \#13 & 0 & 12 & 8 & 4 & 1.00 & 1.5 & 1.5 \\
\hline \#14 (with coal fines) & 0 & 12 & 8 & 4 & 1.00 & 1.5 & 25.4 \\
\hline
\end{tabular}

$\alpha$ is the angle between the face cleat and the maximum horizontal principle stress; $K_{\mathrm{h}}$ is the stress difference coefficient

frequent small fluctuations occurred on the curve, which is due to the formation of some internal branch fractures intersected with the main fracture or connected with the cleats, forming a diversion channel for fracturing fluid (Guo et al. 2014). Since there was a balance between injection and infiltration of the fracturing fluid, the overall pumping pressure curve maintained a relatively stable state.

When the angle between the face cleat and the maximum horizontal principle stress is $30^{\circ}$ (Fig. 6b), the time point of multiple breaking can be found clearly on the curve accompanied by the multi-stage pressure fluctuations. It is evident that in situations where the angle was small, the continuous injection of fracturing fluid made the hydraulic fractures frequently encounter the opening and closing of cleats and form relatively more branch fractures.

When the angle is $60^{\circ}$ (Fig. 6c), it is still possible to spot multiple breaking points and multi-stage pressure fluctuations on the curve. Compared with the case of $30^{\circ}$, the curve fluctuated more sharply, and the opening and closing of the cleats were more frequent, resulting in more fractures.

When the face cleat was perpendicular to the maximum horizontal principle stress (Fig. 6d), no obvious breakdown point was found on the curve. The frequent movement of cleats caused more frequent fluctuations and higher fluctuating range. After the cleat opened, the fracturing fluid flowed along the cleat opening direction, which made no significant increase on the curve.

\subsection{Effects of cleat orientation on fracture morphology}

Figure 7 presents different fracture morphologies at different angles between the face cleat and the maximum horizontal principle stress. In Fig. 7a, the whole specimen initiated and propagated along the direction of the face cleat, forming a main fracture coupled with some branch fractures around the wellbore. The fracture morphology was not complicated when the face cleat is parallel to the maximum horizontal principle stress.

In Fig. 7b, the main fracture propagated along the direction of the maximum horizontal principle stress and a large number of nonlinear branch fractures were formed along the cleat direction. It can be seen that the hydraulic fractures were arrested by butt cleats in the propagation process, making the propagation path relatively complicated.

Figure $7 \mathrm{c}$ presents the case where the angle between the face cleat and the maximum horizontal principle stress is $60^{\circ}$, and the main fracture propagated along the direction of the maximum horizontal principle stress to the boundary of the specimen. Due to the discontinuous butt cleat, "steplike" fractures were formed on both sides of the fracture during the extension of the main fracture, rather than forming an approximately linear fracture like sandstone or shale. Simultaneously, a fracturing zone was formed near the wellbore, with a gradually decreasing width from the borehole to the boundary. The coal near the wellbore fractured into dense cracks. 

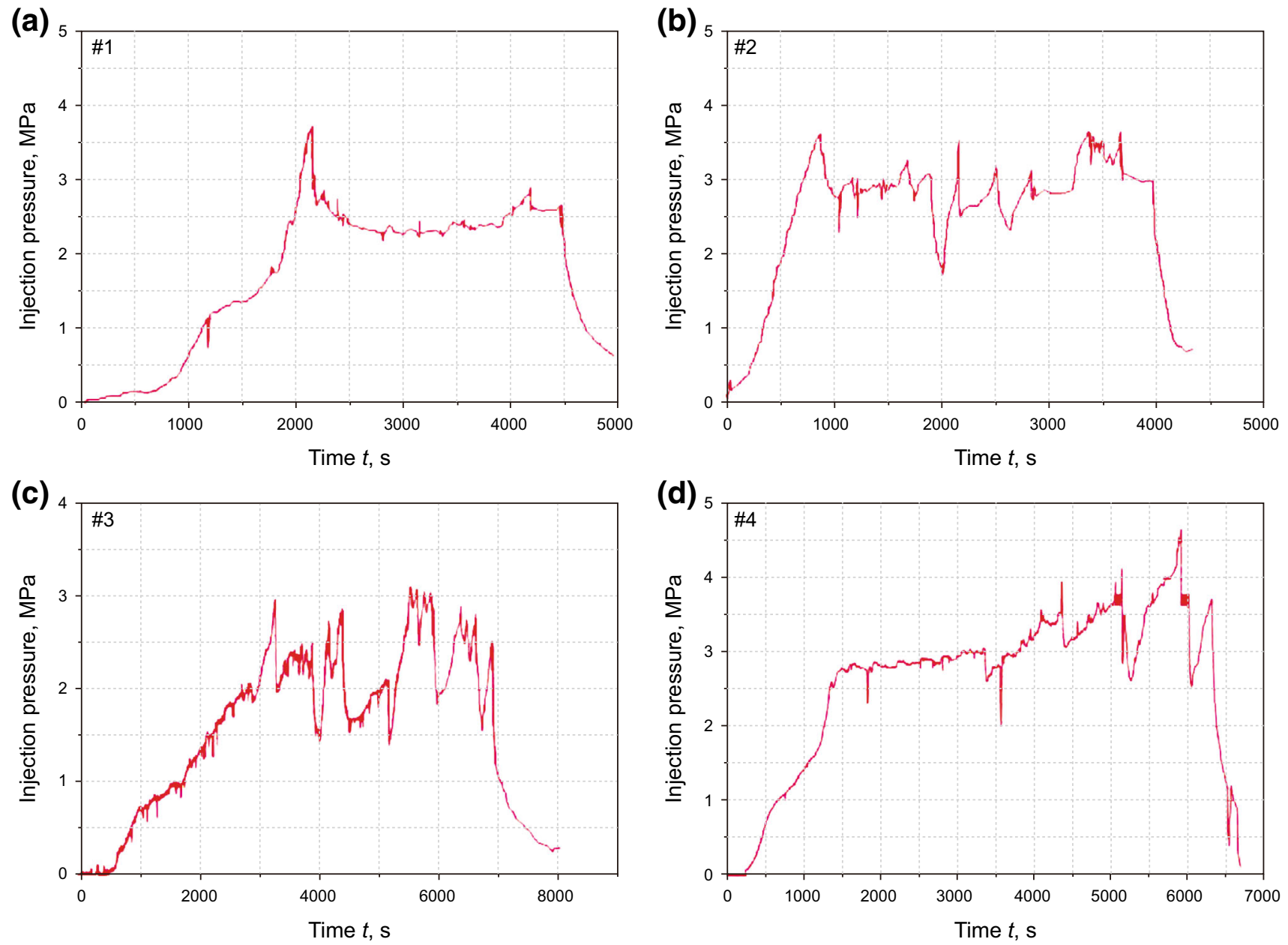

Fig. 6 The pumping pressure curves under different angles between the face cleat and the maximum horizontal principle stress. a $0^{\circ}$, b $30^{\circ}$, c $60^{\circ}$, d $90^{\circ}$

As shown in Fig. 7d, the pumping pressure was not enough to overcome the normal stress generated in the direction of the butt cleat. Therefore, the main fracture traversed the face cleat and extended along the butt cleat. It was more likely to form branch fractures near the wellbore than specimen \#1.

Previous studies (Warpinski and Teufel 1987; Zhou et al. 2008) suggested that the approaching angle between hydraulic fractures and natural fractures determines the propagation direction of fractures to a great extent. The complexity of the fracture morphology in coal seams is significantly influenced by cleats (Fan et al. 2014). As can be seen from the above fracture morphologies (Fig. 7e), the fracture is more complicated and the fracture network forms more easily near the wellbore when the face cleat orientation and the maximum horizontal principle stress is not parallel or orthogonal. Under such conditions, the greater the $\alpha$ is, the more likely the fractures are to propagate along the opening butt cleat and the easier it is to form "step-like" fractures. With the continuous increase and accumulation of new fractures, the new and old fractures finally make the entire specimen fractured.

As well as the qualitative analysis above, a quantitative analysis of the fracture network is also necessary. Fracture number $(\mathrm{FN})$ and area ratio (AR) are selected as two main parameters to quantitatively evaluate the effect of cleat orientation on fracture morphology. Due to the well-developed internal cleat system in coal, it is difficult to distinguish face cleat, butt cleat and hydraulic fractures by CT scanning; thus, the number of fractures with fracturing fluid was carefully observed macroscopically and the relationship between fracture number and cleat orientation has been given. As shown in Fig. 8, the fracture number is the highest when the angle is $60^{\circ}$ compared with the other three angles. Furthermore, the area ratio of a split specimen is selected as a sign of fracture complexity. The area ratio is defined as the ratio of fracturing fluid infiltration area to the actual coal cross-sectional area. The higher the area ratio means the more complex the fracture morphology. The value of area ratio is greater when the angle is $30^{\circ}$ and 

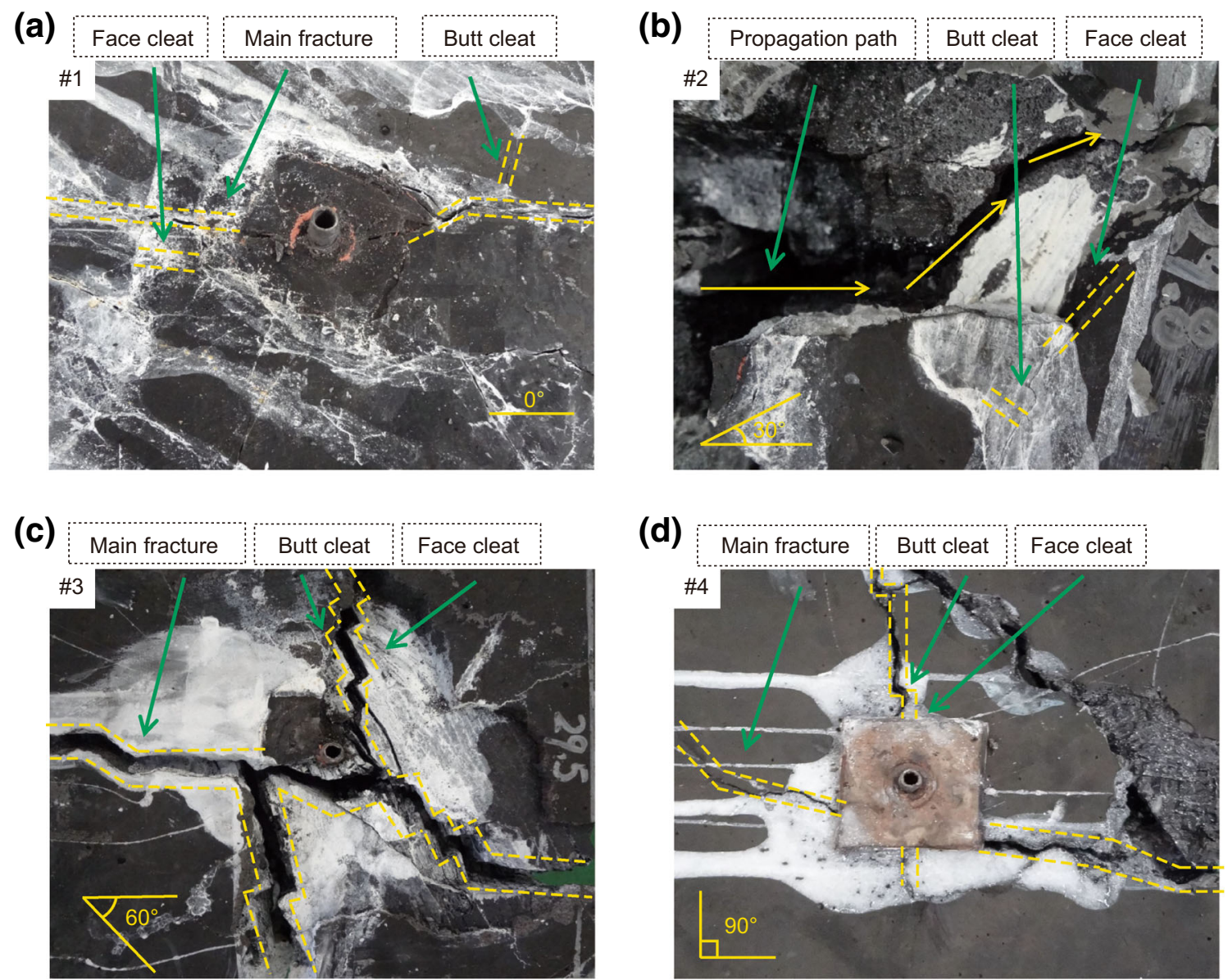

(e)

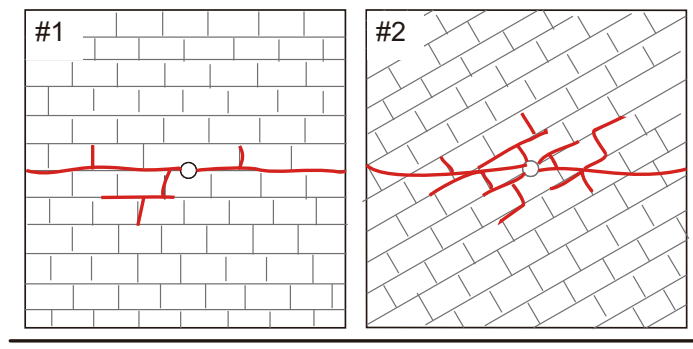

$0^{\circ}$

$30^{\circ}$

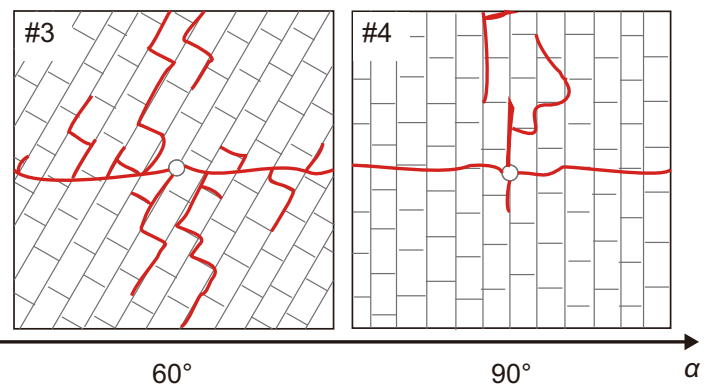

Fig. 7 The fracture morphology at different angles between the face cleat and the maximum horizontal principle stress. a $0^{\circ}, \mathbf{b} 30^{\circ}, \mathbf{c} 60^{\circ}, \mathbf{d} 90^{\circ}$, e 2-D fracture propagation with the increase in $\alpha$ at the horizontal principle stress difference of $4 \mathrm{MPa}$

$60^{\circ}$, and the fracture morphology is the most complex under the case of $60^{\circ}$, forming "step-like" fractures.

\subsection{Effects of in situ stress}

\subsubsection{Effects of horizontal principle stress difference}

Since all experiments were conducted under normal fault stress conditions $\left(\sigma_{\mathrm{v}}>\sigma_{\mathrm{H}}>\sigma_{\mathrm{h}}\right)$, the effect of the horizontal principle stress difference on fracture propagation was investigated in this section. Two groups of experiments were designed: $2 \mathrm{MPa}$ (specimen \#5) and $4 \mathrm{MPa}$ (specimen \#1). It can be seen that the main fracture was formed in specimen \#5 (Fig. 9a), accompanied by extension and diversion along the butt cleat, and the entire morphology was a little more complex compared with a single main fracture in specimen \#1 (Fig. 7a). The higher the horizontal principle stress difference, the simpler the fracture morphology, which is in line with the propagation principle that a high stress difference controls the fracture growth path (Zou et al. 2016). When the stress difference decreased, the fracturing fluid easily flowed into cleats with 


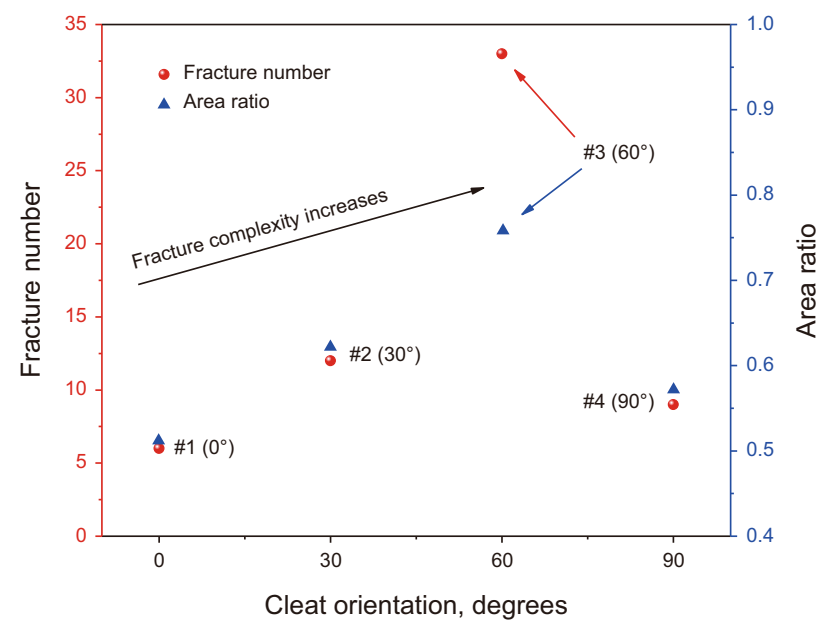

Fig. 8 Variation of fracture number and area ratio with the cleat orientation

lower cementing strength and the fractures tended to divert along the weak cleat, giving rise to more complex fractures. As Tan et al. (2017b) and Mayerhofer et al. (2008) showed in their research, in situ stress plays a major role in controlling the propagation of hydraulic fractures. To get a better fracturing effect, an appropriate stress difference should be ensured during the fracking process. At the same time, in order to make the hydraulic fractures extend farther, traverse more cleats and obtain more complex fractures, the stress difference cannot be set too low.

\subsubsection{Effects of the horizontal principle stress difference coefficient}

The horizontal principle stress difference coefficient is defined as $K_{\mathrm{h}}$, of which the formula is $K_{\mathrm{h}}=\left(\sigma_{\mathrm{H}}-\sigma_{\mathrm{h}}\right) / \sigma_{\mathrm{h}}$. The greater the value of $K_{\mathrm{h}}$, the more evident the horizontal principle stress difference. By comparing specimens \#5, \#6 and \#7, it is evident that two parallel main fractures connected with butt cleats were formed along the face cleat in specimen \#6 (Fig. 9b), whose entire morphology is the most complicated of the three at $2 \mathrm{MPa}$. The main fracture was formed both in specimens \#1 and \#8, while the morphology of specimen \#8 was more complex (Fig. 9d). As for specimens \#1 and \#7, although they shared the same value of $K_{\mathrm{h}}$, the morphology of specimen \#7 was more complicated in virtue of its smaller stress difference (Fig. 9c).

Based on the experimental results, it can be indicated that $K_{\mathrm{h}}$ can control the main fracture propagation direction for specimens under the same horizontal principle stress difference (Fig. 9e). The greater the value, the more obvious the tendency to propagate along the maximum horizontal principle stress (Dehghan et al. 2015b). When $K_{\mathrm{h}}$ is beyond 0.25 , the main fracture is more likely to form along the maximum horizontal principle stress in this study, which is in line with the results of Guo's (2014) research.

Through quantitative analysis of $K_{\mathrm{h}}$ (Fig. 10), it is obvious that the fracture number decreases with an increase in $K_{\mathrm{h}}$ at the same horizontal principle stress difference of 2 and $4 \mathrm{MPa}$, which is consistent with the trend of area ratio. The fracture morphology is the most complex at a $K_{\mathrm{h}}$ of 0.25 , with the greatest fracture number and area ratio. It is also evident that the value of both fracture number and area ratio of specimen at $2 \mathrm{MPa}$ is greater than at $4 \mathrm{MPa}$, indicating a higher fracture complexity.

\subsection{Effects of injection rate}

Injection rate is one of the key technical parameters controlling fracture morphology (Tan et al. 2017a; Wang et al. 2016b). Figure 11 presents different fracture morphologies at different injection rates. There was a single main fracture along the butt cleat in specimen $\# 9$ when the injection rate is $0.5 \mathrm{~mL} / \mathrm{min}$ (Fig. 11a). It is found that most fracturing fluid flowed along cleats or bedding planes when splitting the specimen. The hydraulic fractures cannot be effectively interconnected with cleats and bedding planes, leading the fracturing fluid to penetrate into weak planes, which is in accordance with the findings of Beugelsdijk et al. (2000). When the injection rate increased to $1.5 \mathrm{~mL} / \mathrm{min}$ (Fig. 11c), the fracturing fluid penetrated into the cleat system, making the weak cleats open. The hydraulic fractures extended and diverted along butt cleats, accompanied with the formation of branch fractures. The overall morphology was a little more complex. The morphology was the most complicated in specimen \#11 when the injection rate increased to $15 \mathrm{~mL} / \mathrm{min}$. The fractures initiated from the direction of maximum horizontal principle stress and diverted along the butt cleat during the propagation process, resulting in many branch fractures. On the one hand, a higher injection rate can lead to higher breakdown pressure, which is determined by injection pressure, the stress caused by fracturing fluid loss and the tensile strength of coal. Due to the unique characteristics of coal, well-developed cleats around the wellbore will lead to fracturing fluid loss during the injection process. With an increase in the injection rate, the increasing rate of net pressure will increase as well as the stress caused by loss and the injection pressure, leading to an increase in the breakdown pressure. Morgan et al. (2017) and AlTammar et al. (2018) have confirmed this conclusion through experiments. At the same time, the simulation results obtained by Jung et al. (2014) through $\mathrm{PFC}^{2 \mathrm{D}}$ are also consistent with the conclusion. On the other hand, it can ensure that the main fracture extended along the maximum horizontal principle stress and branch fractures propagated along both sides of 
(a)

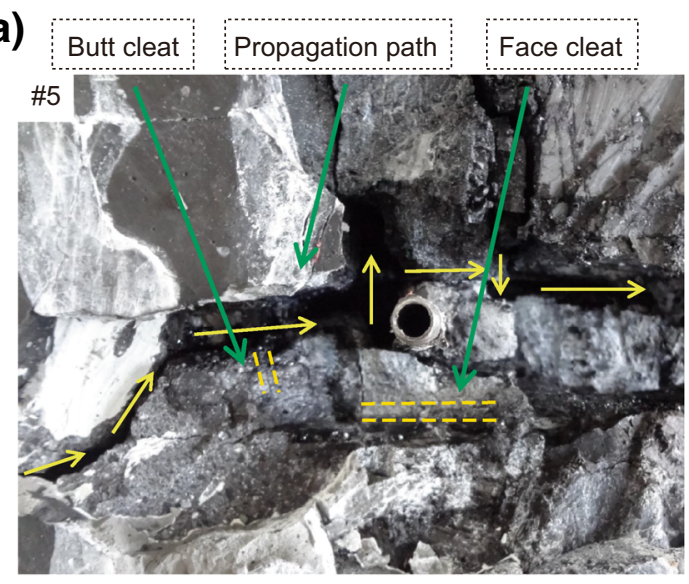

(c)

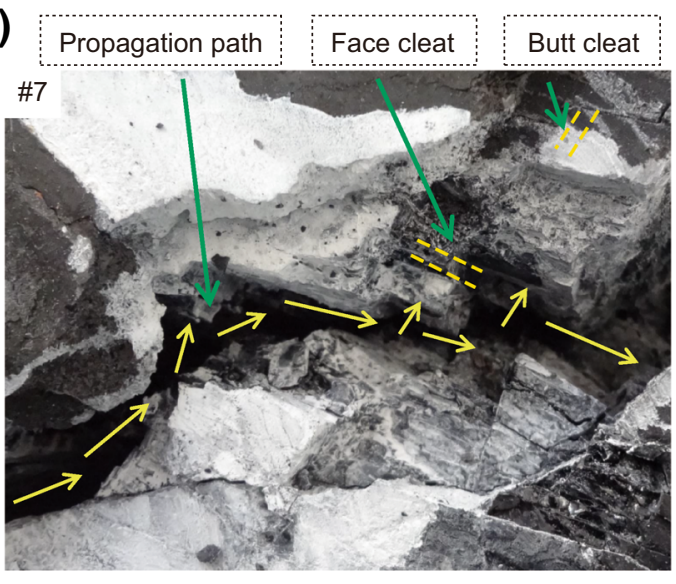

(b)

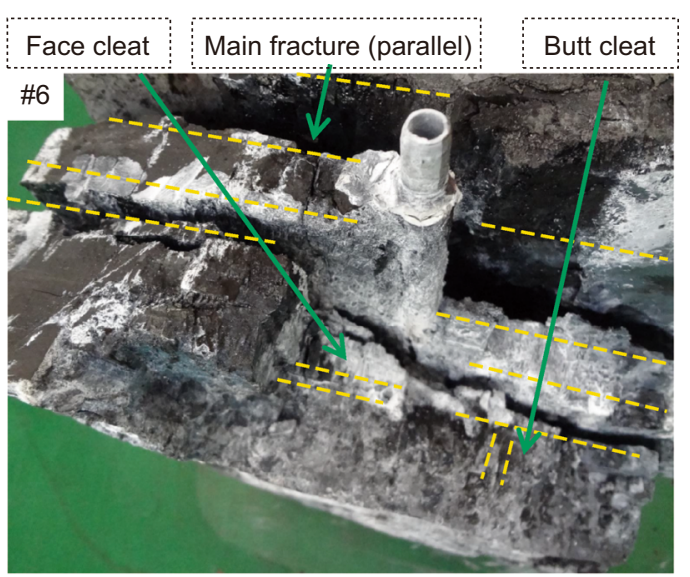

(d)

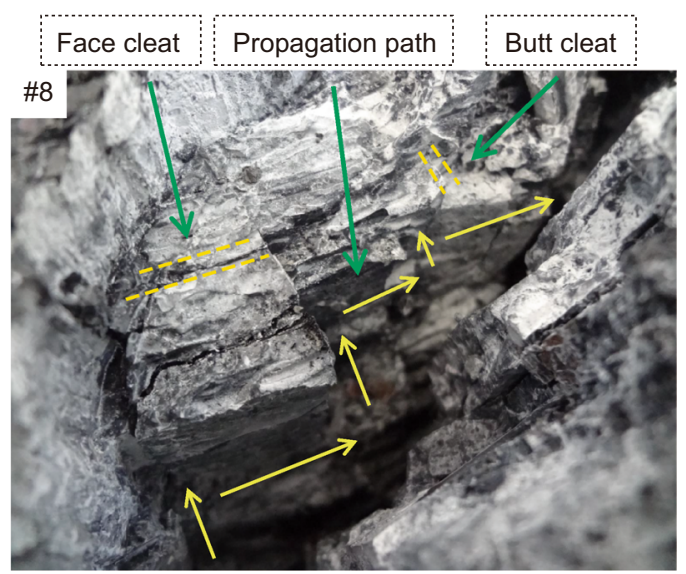

(e)

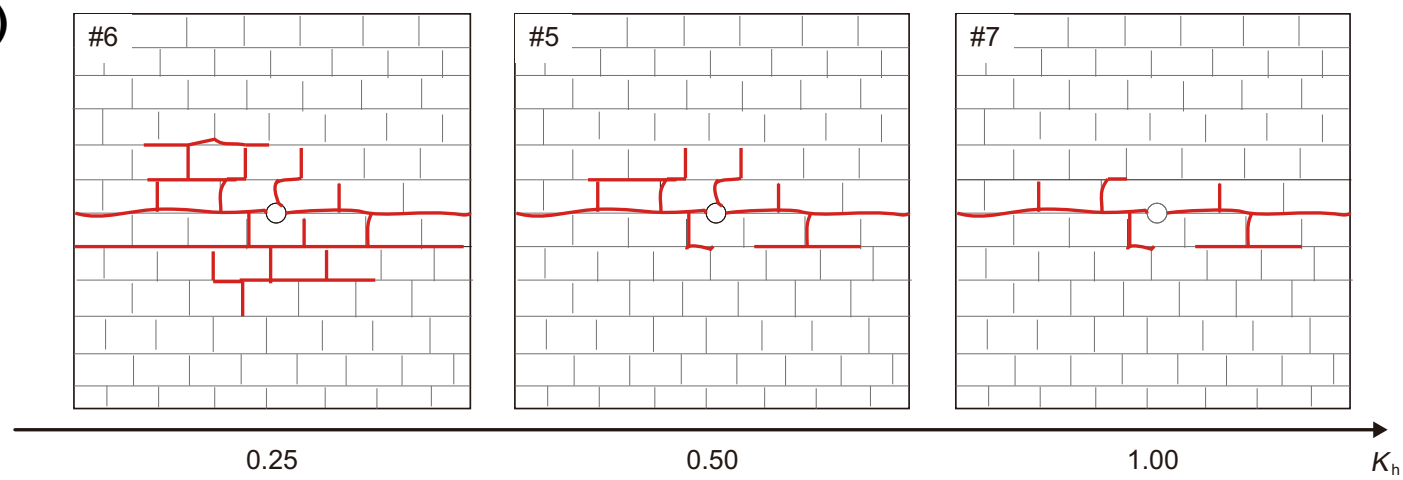

Fig. 9 Fracture morphology of the specimens at different in situ stresses. a $K_{\mathrm{h}}=0.50$, b $K_{\mathrm{h}}=0.25$, c $K_{\mathrm{h}}=1.00$, d $K_{\mathrm{h}}=0.67$, e $2-\mathrm{D}$ fracture propagation with the increase in $K_{\mathrm{h}}$ at the horizontal principle stress difference of $2 \mathrm{MPa}$

it, which is consistent with the simulation results of Zhou's (2016). The hydraulic fractures were well connected with the cleat system, increasing the fracture complexity. However, only one main fracture was formed in specimen \#12 when the face cleat was parallel to the maximum horizontal principle stress at an injection rate of $15 \mathrm{~mL} / \mathrm{min}$ (Fig. 11b). It may be because the injection rate was so high that the hydraulic fracture extended rapidly to the boundary of the specimen, resulting in a rapid energy release. As a consequence, there was no good interaction between hydraulic fractures and the cleat system and the complexity of the fractures was not high.

Figure 12 shows that an appropriate increase in injection rate is conducive to the formation of complex fractures. An excessive injection rate will have little effect, or may even be counterproductive when the face cleat is along the maximum horizontal principle stress. Besides, the fracture 


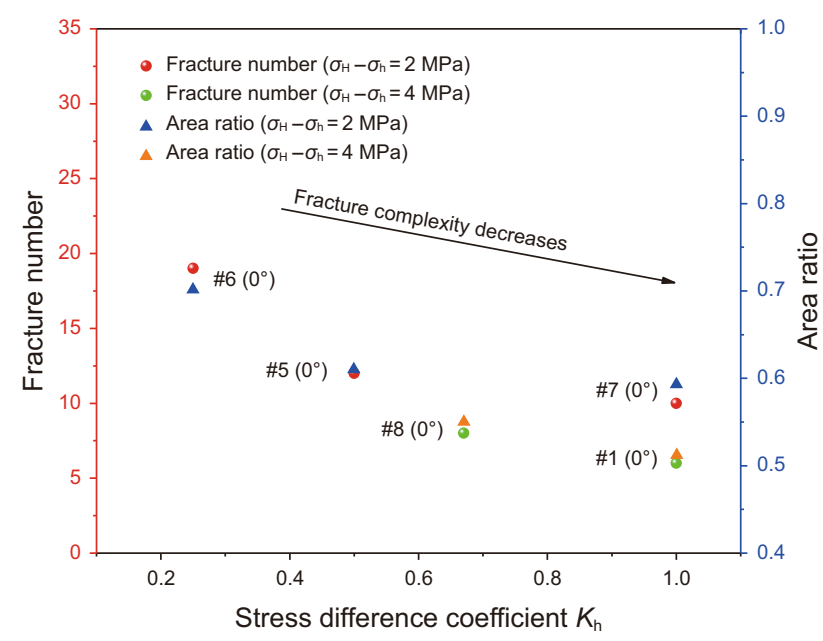

Fig. 10 Variation of fracture number and area ratio with the stress difference coefficient

number and area ratio are greater when the angle is $90^{\circ}$ than $0^{\circ}$ under the same injection rate.

As can be seen from the experimental results, an appropriate injection rate can make the natural cleat system open, while an excessive injection rate will cause hydraulic fractures to extend only in one direction. The interactions between fractures and the cleat system will then be reduced, inhibiting the formation of complex fractures. Within an appropriate range, the higher the injection rate is, the more complicated the fractures are. The existence of butt cleats makes the fracture propagation more complex. With an increase in injection rate, the fractures are more complex when $\alpha$ is $90^{\circ}$ compared with $0^{\circ}$. Since the in situ stress state, the characteristics of the natural cleat system and the bedding plane cannot be changed artificially, the injection rate is the key to get better fracturing effects. A high injection rate can open the natural cleats and create new hydraulic fractures, forming fracture networks. Therefore, the selection of a higher injection rate based on the cleat orientation is of vital importance.

\subsection{Effects of fracturing fluid viscosity}

Two groups of experiments were conducted to discuss the effect of viscosity in this section: $25.4 \mathrm{mPa} s$ (specimen $\# 1$ ) and $1.5 \mathrm{mPa} \mathrm{s}$ (specimen \#13). Each group had the same injection rate $(1.5 \mathrm{~mL} / \mathrm{min})$ and horizontal principle stress difference (4 MPa). The main fracture extended along the direction of maximum horizontal principle stress in each group (Fig. 13b). A single main fracture was more likely to form in specimen \#1, whereas more branch fractures were generated near the wellbore in specimen \#13. It
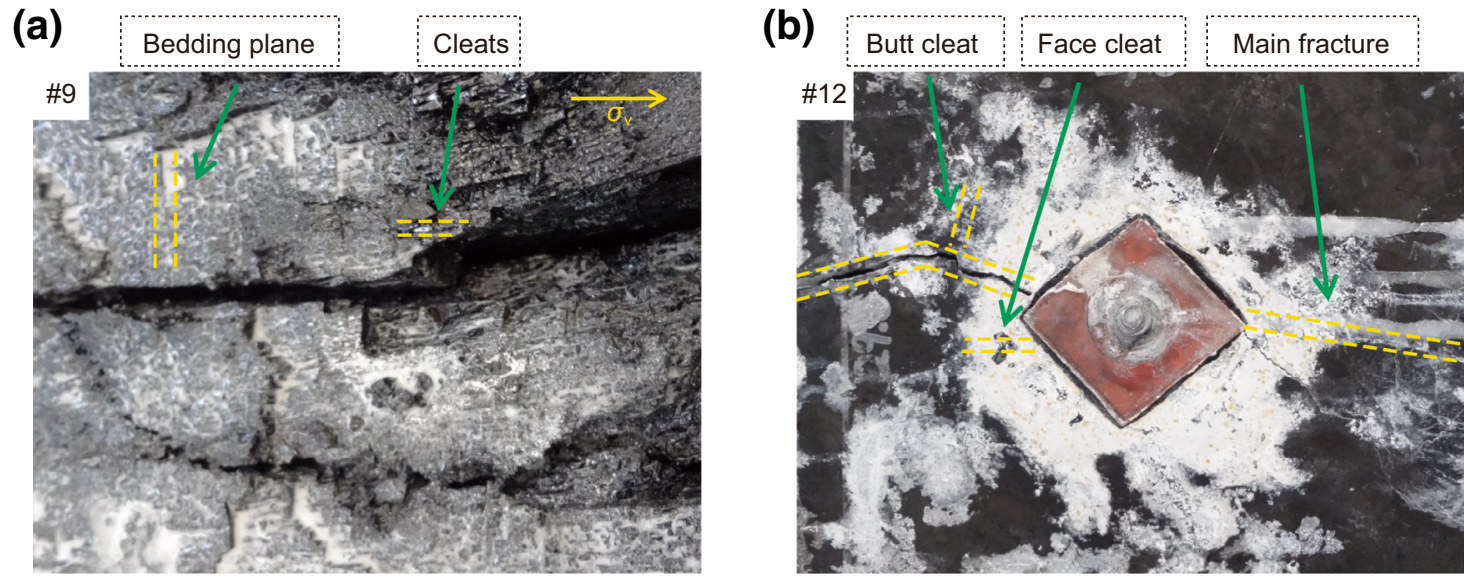

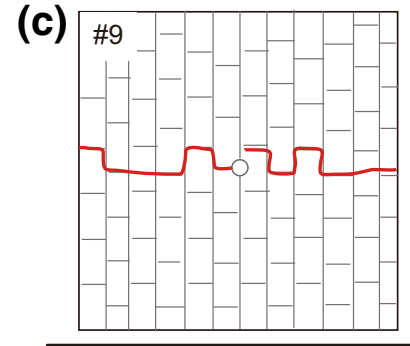

0.5

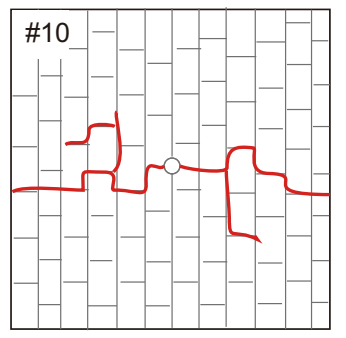

1.5

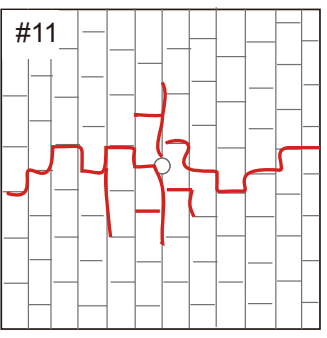

15.0

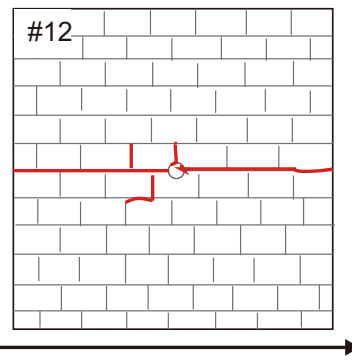

15.0

Fig. 11 Fracture morphology of the specimens at different injection rates. a $0.5 \mathrm{~mL} / \mathrm{min}, \mathbf{b} 15 \mathrm{~mL} / \mathrm{min}$, c 2 -D fracture propagation with the increase in the injection rate under different $\alpha$ 


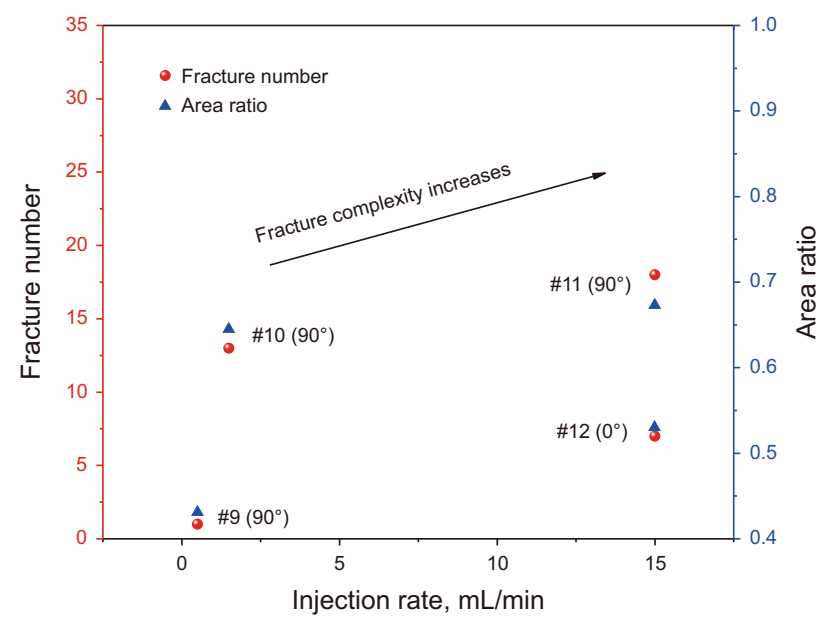

Fig. 12 Variation of fracture number and area ratio with the injection rate

(a)

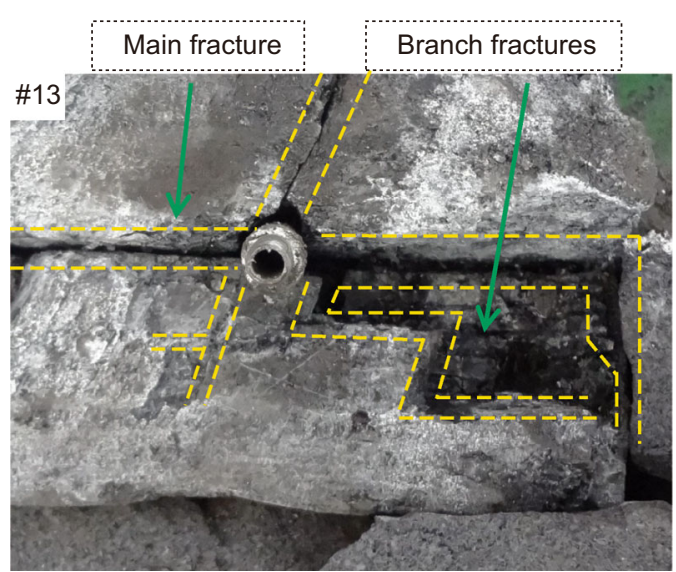

(b)

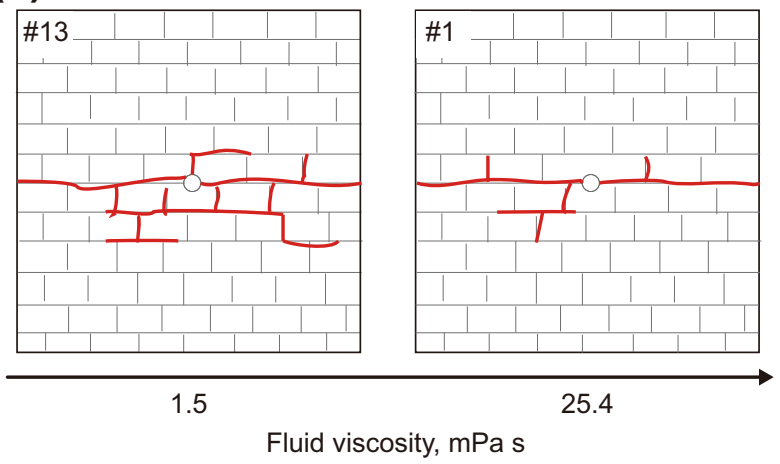

Fig. 13 Fracture morphology under different fluid viscosities. a $1.5 \mathrm{mPa} \mathrm{s}$, b 2-D fracture propagation with the increase in the fluid viscosity at the horizontal principle stress difference of $4 \mathrm{MPa}$

may be because fluid with lower viscosity infiltrates more easily into cleats, generating more complex fractures. Water-frac fluid has been used to generate complex fractures in most stimulations. Cipolla et al. (2009) reported

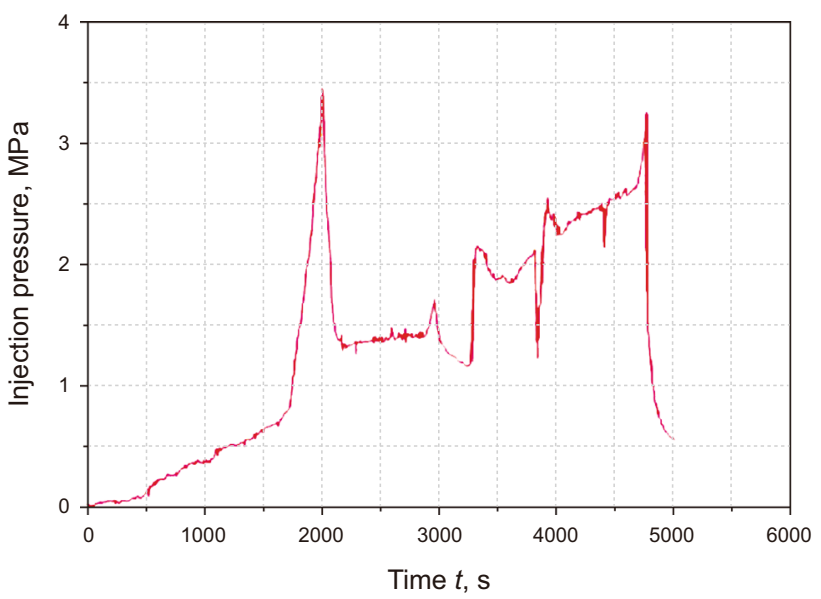

Fig. 14 Pumping pressure curve of specimen \#13

that stimulated reservoir volume created with slick water (a fracturing fluid) was roughly 3.4 times that of cross-linked gel (a fracturing fluid) and validated by gas production in the Barnett shale. Active water and other low-viscosity fracturing fluids have been widely used in CBM reservoirs (Ma et al. 2014) to keep the natural cleats open to connect with hydraulic fractures, increasing the complexity of the fractures. Gomaa et al. (2014) noted that the fracturing fluid type can strongly determine the degree of fracture complexity. The lower the viscosity is, the more complex the fractures are.

Figure 14 presents the pumping pressure curve of specimen \#13, from which we can see that both the initiating and propagating pressures were lower than in specimen \#1 (Fig. 6a). Fracturing fluid with low viscosity is more likely to infiltrate into the coal matrix, which decreases the effective stress, promoting the generation and propagation of fractures.

As shown in Fig. 15, the lower the fluid viscosity, the greater the fracture number and area ratio and the greater the possibility of forming complex fractures. It is obvious that fracturing fluid with low viscosity can make cleats open and facilitate interactions between hydraulic fractures and cleats, which can enhance the stimulated volume of the reservoir.

In consequence, mixed-fracturing fluid is recommended in the fracking process. Fracturing fluid with high viscosity is used in the initial period of fracturing to form obvious main fractures, while fracture networks are formed at a distance from the wellbore with low-viscosity fracturing fluid subsequently. In this way, the interactions between hydraulic fractures and natural fractures can be enhanced to expand the stimulated reservoir volume. Moreover, the hydraulic fractures and the wellbore can be effectively connected, further improving the fracturing effects. 


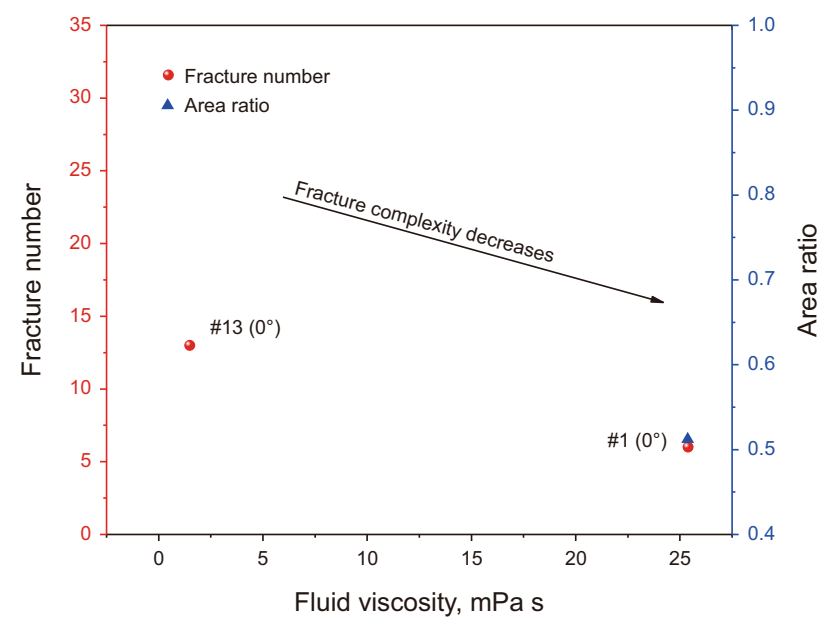

Fig. 15 Variation of fracture number and area ratio with the fluid viscosity

\subsection{Effects of coal fines}

A large amount of coal fines was generated during drilling process, which is difficult to clean up. The influence of coal fines on fracture morphology and subsequent fracturing effects were analyzed through two groups of experiments. Both cleaned specimen \#1 and uncleaned specimen \#14 were set with an injection rate of $1.5 \mathrm{~mL} / \mathrm{min}$, a horizontal stress difference of $4 \mathrm{MPa}$ and a fracturing fluid viscosity of $25.4 \mathrm{mPa}$ s. From the fracture morphology, it can be seen clearly that the main fracture was formed in specimen \#1, accompanied with branch fractures near the wellbore in Fig. 7a. As for specimen \#14, the fractures were disorganized and no obvious main fracture is found in Fig. 16a, c. Coal fines was not dispersed in the fracturing fluid but gathered in front of the fractures (Fig. 16b), resulting in abnormal fracture extension and propagation. As can be seen by comparison, the existence of coal fines hinders the fracturing effects and easily forms a resistant barrier on the leading edge of the fractures, resulting in the failure to produce effective fracture channels in coal. Fractures cannot be interconnected effectively, and no fracture network is generated.

\section{Conclusions}

In this paper, investigation of the effects of different face cleat orientations, in situ stress, injection rate, fracturing fluid viscosity and the existence of coal fines on fracture extension mechanisms was undertaken on raw coal specimens. The main conclusions are summarized as follows.

1. The most complex fractures are generated by the interactions between fractures and cleats. A large (a)

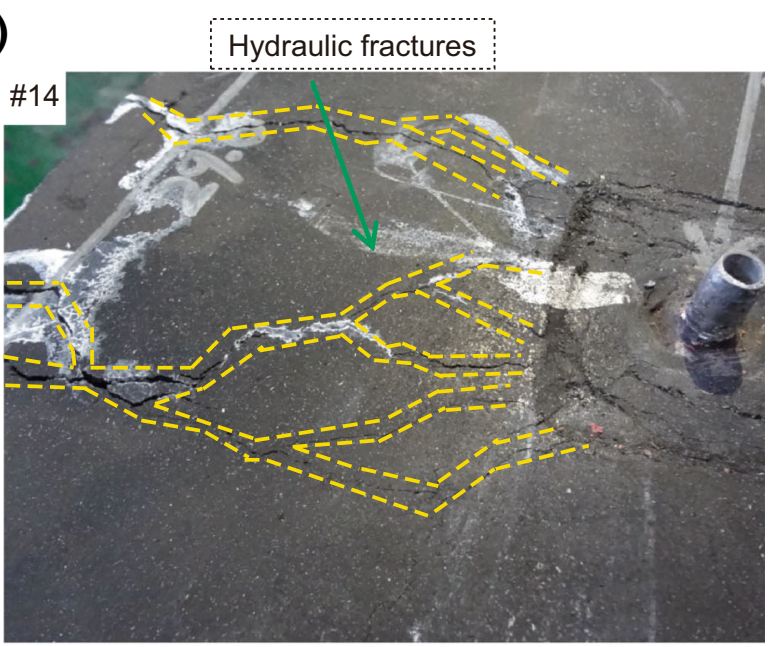

(b)

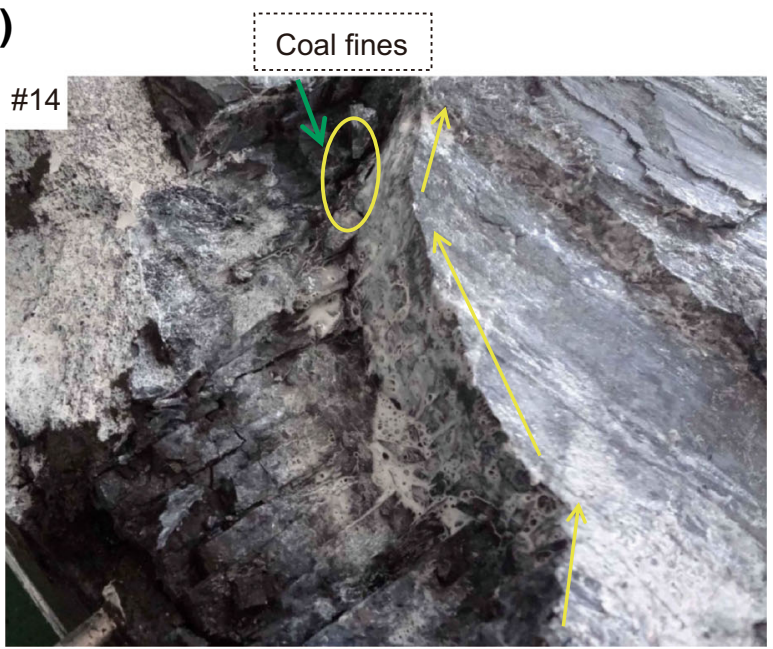

(c)

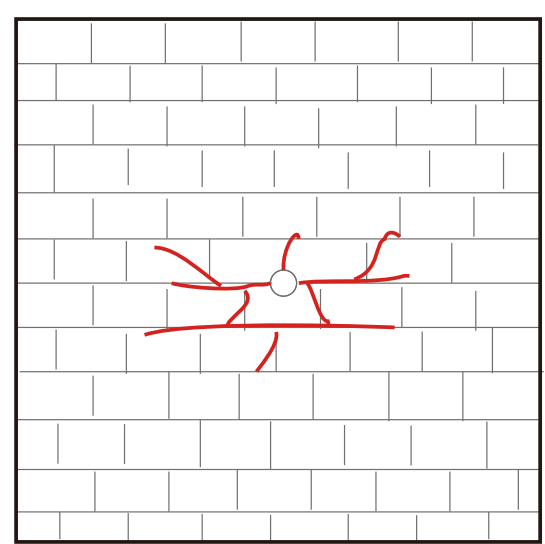

Fig. 16 Fracture morphology of specimen \#14

number of nonlinear branch fractures are formed near the wellbore when the face cleat and the maximum horizontal principle stress are not parallel or orthogonal. The greater the angle between the maximum horizontal principle stress and the face cleat, the more 
likely the fractures are to propagate along the butt cleat and the more complex the "step-like" factures.

2. The greater the maximum horizontal principle stress difference, the greater the value of $K_{\mathrm{h}}$, the simpler the fracture morphology, and the more obvious the tendency to propagate along the maximum horizontal principle stress. It is advantageous to maintain an appropriate stress difference to generate fracture networks during fracking.

3. An increase in the injection rate is beneficial to generate fracture networks due to the butt cleat. The fractures are more complex with an increase in the injection rate when $\alpha$ is $90^{\circ}$ compared with $0^{\circ}$. Fluid with low viscosity is more likely to infiltrate into coal matrix, facilitating fracture generation and propagation.

4. The existence of coal fines inhibits fracturing. The residual coal fines in the wellbore needs to be cleaned up before fracturing to improve the subsequent fracturing effects and enhance the production of CBM wells.

Acknowledgements The study was funded by the National Science and Technology Major Project of China (2016ZX05046004-003) and Northeast Petroleum University Innovation Foundation for Postgraduate (YJSCX2017-010NEPU and YJSCX2017-009NEPU).

Open Access This article is distributed under the terms of the Creative Commons Attribution 4.0 International License (http://creative commons.org/licenses/by/4.0/), which permits unrestricted use, distribution, and reproduction in any medium, provided you give appropriate credit to the original author(s) and the source, provide a link to the Creative Commons license, and indicate if changes were made.

\section{References}

Abass HH, Hedayati S, Kim CM. Mathematical and experimental simulation of hydraulic fracturing in shallow coal seams. In: SPE eastern regional meeting, 22-25 October, Lexington, Kentucky. 1991. https://doi.org/10.2118/23452-MS.

Abass HH, van Domelen ML, El Rabaa WM. Experimental observations of hydraulic fracture propagation through coal blocks. In: SPE eastern regional meeting, 31 October-2 November, Columbus, Ohio. 1990. https://doi.org/10.2118/21289-MS.

Alexis DA, Karpyn ZT, Ertekin T, Crandall D. Fracture permeability and relative permeability of coal and their dependence on stress conditions. J Unconv Oil Gas Resour. 2015;10:1-10. https://doi. org/10.1016/j.juogr.2015.02.001.

AlTammar MJ, Gala D, Sharma MM, McAndrew J. Laboratory visualization of fracture initiation and propagation using compressible and incompressible fracturing fluids. J Nat Gas Sci Eng. 2018;55:542-60. https://doi.org/10.1016/j.jngse.2018.05. 010.

Beugelsdijk LJL, de Pater CJ, Sato K. Experimental hydraulic fracture propagation in a multi-fractured medium. In: SPE Asia Pacific conference on integrated modelling for asset management, 25-26 April, Yokohama, Japan. 2000. https://doi. org/10.2118/59419-MS.

Blanton TL. Propagation of hydraulically and dynamically induced fractures in naturally fractured reservoirs. In: SPE unconventional gas technology symposium, 18-21 May, Louisville, Kentucky. 1986. https://doi.org/10.2118/15261-MS.

Chitrala Y, Moreno C, Sondergeld C, Rai C. An experimental investigation into hydraulic fracture propagation under different applied stresses in tight sands using acoustic emissions. J Pet Sci Eng. 2013;108:151-61. https://doi.org/10.1016/j.petrol.2013.01. 002.

Cipolla CL, Lolon EP, Dzubin B. Evaluating stimulation effectiveness in unconventional gas reservoirs. In: SPE annual technical conference and exhibition, 4-7 October, New Orleans, Louisiana. 2009. https://doi.org/10.2118/124843-MS.

de Pater CJ, Beugelsdijk LJL. Experiments and numerical simulation of hydraulic fracturing in naturally fractured rock. In: The 40th U.S. symposium on rock mechanics (USRMS), 25-29 June, Anchorage, Alaska, 2005.

Dehghan AN, Goshtasbi K, Ahangari K, Yan J. Experimental investigation of hydraulic fracture propagation in fractured blocks. Bull Eng Geol Environ. 2015a;74(3):887-95. https://doi. org/10.1007/s10064-014-0665-x.

Dehghan AN, Goshtasbi K, Ahangari K, Yan J. The effect of natural fracture dip and strike on hydraulic fracture propagation. Int $\mathrm{J}$ Rock Mech Min. 2015b;75:210-5. https://doi.org/10.1016/j. ijrmms.2015.02.001.

Deng JQ, Lin C, Yang Q, Liu YR, Tao ZF, Duan HF. Investigation of directional hydraulic fracturing based on true tri-axial experiment and finite element modeling. Comput Geotech. 2016;75:28-47. https://doi.org/10.1016/j.compgeo.2016.01.018.

Ding Y, Liu XJ, Luo PY. The analytical model of hydraulic fracture initiation for perforated borehole in fractured formation. J Pet Sci Eng. 2018;162:502-12. https://doi.org/10.1016/j.petrol.2017.10. 008.

Fan TG, Zhang GQ, Cui JB. The impact of cleats on hydraulic fracture initiation and propagation in coal seams. Pet Sci. 2014;11(4):532-9. https://doi.org/10.1007/s12182-014-0369-7.

Fu W, Ames BC, Bunger AP, Savitski AA. Impact of partially cemented and non-persistent natural fractures on hydraulic fracture propagation. Rock Mech Rock Eng. 2016;49(11):4519-26. https://doi. org/10.1007/s00603-016-1103-0.

Gomaa AM, Qi Q, Maharidge R, Nelson S, Reed T. New insights into hydraulic fracturing of shale formations. In: International petroleum technology conference, 19-22 January, Doha, Qatar. 2014. https://doi.org/10.2523/IPTC-17594-MS.

Guo TK, Zhang SC, Qu ZQ, Zhou T, Xiao YS, Gao J. Experimental study of hydraulic fracturing for shale by stimulated reservoir volume. Fuel. 2014;128:373-80. https://doi.org/10.1016/j.fuel. 2014.03.029.

Hou B, Chen M, Wang Z, Yuan JB, Liu M. Hydraulic fracture initiation theory for a horizontal well in a coal seam. Pet Sci. 2013;10(2):219-25. https://doi.org/10.1007/s12182-013-0270-9.

Huang SP, Liu DM, Yao YB, Gan Q, Cai YD, Xu LL. Natural fractures initiation and fracture type prediction in coal reservoir under different in situ stresses during hydraulic fracturing. J Nat Gas Sci Eng. 2017;43:69-80. https://doi.org/10.1016/j.jngse. 2017.03.022.

Jiang TT, Zhang JH, Wu H. Experimental and numerical study on hydraulic fracture propagation in coalbed methane reservoir. J Nat Gas Sci Eng. 2016;35:455-67. https://doi.org/10.1016/j. jngse.2016.08.077.

Jung J, Heo C, Jeon S. Study on hydraulic fracturing evolution under various fluid viscosity and injection rate. In: ISRM international symposium-8th Asian rock mechanics symposium, 14-16 October, Sapporo, Japan, 2014. 
Liang W, Wu P, Li Z. Study on hydraulic fracturing of large-size coal mass containing natural macro-fracture. In: The 50th U.S. rock mechanics/geomechanics symposium, 26-29 June, Houston, Texas, 2016.

Liang YP, Cheng YH, Zou QL, Wang WD, Ma YK, Li QG. Response characteristics of coal subjected to hydraulic fracturing: an evaluation based on real-time monitoring of borehole strain and acoustic emission. J Nat Gas Sci Eng. 2017;38:402-11. https:// doi.org/10.1016/j.jngse.2017.01.001.

Lin $\mathrm{C}$, He JM, Li X, Wan XL, Zheng B. An experimental investigation into the effects of the anisotropy of shale on hydraulic fracture propagation. Rock Mech Rock Eng. 2017;50(3):543-54. https://doi.org/10.1007/s00603-016-1136-4.

Liu ZY, Chen M, Zhang GQ. Analysis of the influence of a natural fracture network on hydraulic fracture propagation in carbonate formations. Rock Mech Rock Eng. 2014;47(2):575-87. https:// doi.org/10.1007/s00603-013-0414-7.

Lu YY, Cheng YG, Ge ZL, Cheng L, Zuo SJ, Zhong JY. Determination of fracture initiation locations during crossmeasure drilling for hydraulic fracturing of coal seams. Energies. 2016;9(5):358. https://doi.org/10.3390/en9050358.

Ma CC, Jiang YP, Xing HL, Li TB. Numerical modelling of fracturing effect stimulated by pulsating hydraulic fracturing in coal seam gas reservoir. J Nat Gas Sci Eng. 2017a;46:651-63. https://doi.org/10.1016/j.jngse.2017.08.016.

Ma G, Su XB, Lin HX, Guo HY, Tao YQ, Liu X. Theory and technique of permeability enhancement and coal mine gas extraction by fracture network stimulation of surrounding beds and coal beds. Nat Gas Ind B. 2014;1(2):197-204. https://doi. org/10.1016/j.ngib.2014.11.012.

Ma XF, Zou YS, Li N, Chen M, Zhang YN, Liu ZZ. Experimental study on the mechanism of hydraulic fracture growth in a glutenite reservoir. J Struct Geol. 2017b;97:37-47. https://doi. org/10.1016/j.jsg.2017.02.012.

Mayerhofer MJ, Lolon E, Warpinski NR, Cipolla CL, Walser DW, Rightmire CM. What is stimulated rock volume? In: SPE shale gas production conference, 16-18 November, Fort Worth, Texas, USA. 2008. https://doi.org/10.2118/119890-MS.

Morgan SP, Li BQ, Einstein HH. Effect of injection rate on hydraulic fracturing of Opalinus clay shale. In: The 51st U.S. rock mechanics/geomechanics symposium, 25-28 June, San Francisco, California, USA, 2017.

Porcu MM, Ajao O, Dalamarinis P, Economides MJ. On the economic optimization of the fracturing of coal seam reservoirs. In: SPE Asia Pacific oil and gas conference and exhibition, 22-24 October, Jakarta, Indonesia. 2013. https://doi.org/10.2118/ 165804-MS

Qin L, Zhai C, Liu SM, Xu JZ. Mechanical behavior and fracture spatial propagation of coal injected with liquid nitrogen under triaxial stress applied for coalbed methane recovery. Eng Geol. 2018;233:1-10. https://doi.org/10.1016/j.enggeo.2017.11.019.

Song CP, Lu YY, Jia YZ. Study on the natural fracture's effect on hydraulic crack's propagation in coal seam. In: ISRM international symposium-8th Asian rock mechanics symposium, 14-16 October, Sapporo, Japan, 2014.

Taleghani AD, Gonzalez M, Shojaei A. Overview of numerical models for interactions between hydraulic fractures and natural fractures: challenges and limitations. Comput Geotech. 2016;71:361-8. https://doi.org/10.1016/j.compgeo.2015.09.009.

Tan P, Jin Y, Han K, Hou B, Chen M, Guo XF, Gao J. Analysis of hydraulic fracture initiation and vertical propagation behavior in laminated shale formation. Fuel. 2017a;206:482-93. https://doi. org/10.1016/j.fuel.2017.05.033.
Tan P, Jin Y, Han K, Zheng XJ, Hou B, Gao J, Chen M, Zhang YY. Vertical propagation behavior of hydraulic fractures in coal measure strata based on true triaxial experiment. J Pet Sci Eng. 2017b;158:398-407. https://doi.org/10.1016/j.petrol.2017.08. 076.

Tan P, Jin Y, Hou B, Zheng XJ, Guo XF, Gao J. Experiments and analysis on hydraulic sand fracturing by an improved true triaxial cell. J Pet Sci Eng. 2017c;158:766-74. https://doi.org/10. 1016/j.petrol.2017.09.004.

Wang HY, Xia BW, Lu YY, Gong T, Zhang R. Study on the propagation laws of hydrofractures meeting a faulted structure in the coal seam. Energies. 2017;10(5):654. https://doi.org/10.3390/ en10050654.

Wang T, Hu WR, Elsworth D, Zhou W, Zhou WB, Zhao XY, Zhao LZ. The effect of natural fractures on hydraulic fracturing propagation in coal seams. J Pet Sci Eng. 2016a;150:180-90. https://doi.org/10.1016/j.petrol.2016.12.009.

Wang WD, Su YL, Zhang Q, Xiang G, Cui SM. Performance-based fractal fracture model for complex fracture network simulation. Pet Sci. 2018;15(1):126-34. https://doi.org/10.1007/s12182-0170202-1.

Wang Y, Li X, Zhang B. Analysis of fracturing network evolution behaviors in random naturally fractured rock blocks. Rock Mech Rock Eng. 2016b;49(11):4339-47. https://doi.org/10.1007/ s00603-016-1023-z.

Warpinski NR, Teufel LW. Influence of geologic discontinuities on hydraulic fracture propagation (includes associated papers 17011 and 17074). J Pet Technol. 1987;39(02):209-20. https://doi.org/ 10.2118/13224-PA.

Westwood RF, Toon SM, Cassidy NJ. A sensitivity analysis of the effect of pumping parameters on hydraulic fracture networks and local stresses during shale gas operations. Fuel. 2017;203:843-52. https://doi.org/10.1016/j.fuel.2017.05.004.

Wright CA, Tanigawa JJ, Mei SX, Li ZG. Enhanced hydraulic fracture technology for a coal seam reservoir in central China. In: International meeting on petroleum engineering, 14-17 November, Beijing, China. 1995. https://doi.org/10.2118/ 29989-MS.

Wu YT, Pan ZJ, Zhang DY, Down DI, Lu ZH, Connell LD. Experimental study of permeability behaviour for proppant supported coal fracture. J Nat Gas Sci Eng. 2018;51:18-26. https://doi.org/10.1016/j.jngse.2017.12.023.

Yao Y, Wang W, Keer LM. An energy based analytical method to predict the influence of natural fractures on hydraulic fracture propagation. Eng Fract Mech. 2018;189:232-45. https://doi.org/ 10.1016/j.engfracmech.2017.11.020.

Zhang J. Numerical simulation of hydraulic fracturing coalbed methane reservoir. Fuel. 2014;136:57-61. https://doi.org/10. 1016/j.fuel.2014.07.013.

Zhang XD, Zhang S, Yang YL, Zhang P, Wei GY. Numerical simulation by hydraulic fracturing engineering based on fractal theory of fracture extending in the coal seam. J Nat Gas Geosci. 2016;1(4):319-25. https://doi.org/10.1016/j.jnggs.2016.08.006.

Zhao XZ, Liu SQ, Sang SX, Pan ZJ, Zhao WX, Yang YH, Hu QJ, Yang YL. Characteristics and generation mechanisms of coal fines in coalbed methane wells in the southern Qinshui Basin, China. J Nat Gas Sci Eng. 2016;34:849-63. https://doi.org/10. 1016/j.jngse.2016.07.063.

Zhou J, Chen M, Jin Y, Zhang GQ. Analysis of fracture propagation behavior and fracture geometry using a tri-axial fracturing system in naturally fractured reservoirs. Int J Rock Mech Min. 2008;45(7):1143-52. https://doi.org/10.1016/j.ijrmms.2008.01. 001. 
Zhou J, Zhang LQ, Pan ZJ, Han ZH. Numerical investigation of fluiddriven near-borehole fracture propagation in laminated reservoir rock using PFC 2D. J Nat Gas Sci Eng. 2016;36:719-33. https:// doi.org/10.1016/j.jngse.2016.11.010.

Zou JP, Chen WZ, Yuan JQ, Yang DS, Yang JP. 3-D numerical simulation of hydraulic fracturing in a CBM reservoir. J Nat Gas
Sci Eng. 2017;37:386-96. https://doi.org/10.1016/j.jngse.2016. 11.004.

Zou YS, Zhang SC, Zhou T, Zhou X, Guo TK. Experimental investigation into hydraulic fracture network propagation in gas shales using CT scanning technology. Rock Mech Rock Eng. 2016;49(1):33-45. https://doi.org/10.1007/s00603-015-0720-3. 